\title{
APORTACIONES A LA HISTORIA \\ DEL DESAPARECIDO TEATRO POWER
}

\author{
Jesús Rodríguez Bravo \\ José Manuel Santos Rodríguez
}

\section{RESUMEN}

El Teatro Power fue el gran teatro de La Orotava durante casi un siglo. Fue establecido en la iglesia del antiguo convento de San Nicolás Obispo y se convirtió en punto de referencia del mundo del espectáculo en el valle de La Orotava. Por su escenario desfilaron artistas nacionales e internacionales; en él se organizaron grandes espectáculos teatrales, literarios o sociales; y fue el primer cine de la población, donde se estrenaron los nuevos proyectores llegados de Europa. Fue remodelado varias veces para poder adaptarlo a las exigencias técnicas, y para mejorarlo se diseńaron dos interesantes proyectos arquitectónicos que contaron con las propuestas de los arquitectos Mariano Estanga y Enrique Marrero Regalado, pero que nunca se realizaron. El paso del tiempo, la irrupción de salas construidas expresamente para este tipo de espectáculos y la desidia lo hicieron desaparecer a mediados del siglo xx, cuando la preocupación por el patrimonio comenzaba a ser importante.

Palabras Clave: Teatro Power, La Orotava, convento, arquitectura, espectáculo teatral.

\author{
CONTRIBUTIONS TO THE HISTORY \\ OF THE DISAPPEARED POWER THEATRE
}

\section{Abstract}

The Power Theatre was the greatest theatre of La Orotava for almost a century. It was built in the church of the old convent of San Nicolás Obispo and became a point of reference for the entertainment world in The Orotava Valley. National and international artists performed on its stage; great theatrical, literary and social shows were organized on it; and it was the first cinema of the town, where the new projectors from Europe were premiered. It was remodeled several times in order to adapt it to technical requirements; and to improve it, two interesting architectural projects were designed with the proposals of the architects Mariano Estanga and Enrique Marrero Regalado, but they were never carried out. With the passing of time, the irruption of theatres built specifically for this type of spectacle brought about its decline in the middle of the 20th century, when the concern for cultural heritage began to become important.

Keywords: Teatro Power, La Orotava, architecture, theatre show. 


\section{INTRODUCCIÓN}

Cuando en 1953 se derribaron la iglesia y buena parte del convento de San Nicolás Obispo de La Orotava, también desapareció la posibilidad de recuperar parte de nuestro legado artístico y de nuestra historia cultural. Aquel hecho, fruto del olvido y la ignorancia, consumó un proceso difícil para el edificio pero que había sido enriquecedor para el desarrollo histórico de la población. La devoción, el fuego, el espectáculo y el tiempo se habían sucedido para configurar el último capítulo de una historia que había ido gestándose a lo largo de más de trescientos años.

Ubicado en aquella iglesia demolida a mediados del siglo xx, el Teatro Power fue la primera sala de este tipo con la que contó La Orotava y una de las pioneras en Tenerife en ofrecer espectáculos de forma regular, incluidas las proyecciones cinematográficas. Desarrolló su labor entre 1855 y 1953 aproximadamente, aunque en los últimos años permaneció largos períodos cerrado y no sobrevivió a los cambios arquitectónicos derivados de la evolución de las normas de exhibición, ni a la presión de un urbanismo aún carente de la preocupación patrimonial que hoy defendemos.

Este antiguo convento tuvo sus orígenes en el transcurrir del siglo XvII, período que en Canarias constituyó una época determinante para la expansión religiosa y la consolidación de los sectores nobiliarios, lo que provocó la apertura de numerosas comunidades de frailes y monjas que dibujaron sobre el terreno un panorama conventual que basaba su establecimiento en la situación económica, la devoción o el afianzamiento de algunas élites sociales. En el marco de ese planteamiento debe entenderse la fundación en 1626 del convento dominico de San Nicolás Obispo de la mano de Nicolás de Cala, aunque sufrió diversos problemas de patronazgo hasta que en 1632 Diego Benítez de Lugo y su esposa se hicieron cargo del mismo. A partir de ese momento el desarrollo experimentado por la comunidad religiosa de monjas catalinas, amparado en las continuas dotaciones, no hizo más que crecer tanto económica como artísticamente, constituyéndose en un punto urbano definitorio de una gran manzana marcada por la fuerte pendiente de la calle Cólogan. Abierto a través de su iglesia a la plaza principal del pueblo, conocida durante mucho tiempo como plaza de las Monjas, formaba un definido triángulo urbano junto con la antigua iglesia de la Concepción y las casas de Celada, Machado y Cólogan; con un fuerte carácter como lugar abierto donde tenían lugar las principales celebraciones.

El monasterio creció considerablemente pero también sufrió tres terribles incendios. El primero y más significativo, en agosto de 1716, cuando el fuego no solo acabó con el convento, sino también con el contiguo palacio de Celada, cuyas ruinas permanecieron en aquel lugar hasta 1895 . Fue reconstruido pero volvió a quemarse en julio de 1761. Arreglado de nuevo, sufriría un tercer incendio en octubre de 1815, pero aunque fue reedificado bajo la dirección de José de Betancourt y Castro, nunca volvió a recuperar el volumen constructivo anterior.

La decadencia sufrida por las órdenes monásticas desde finales del siglo XVIII culminó con los procesos desamortizadores del siglo xix. Como en otros casos similares, el convento de San Nicolás fue desamortizado en 1826, pasando a ser sede 


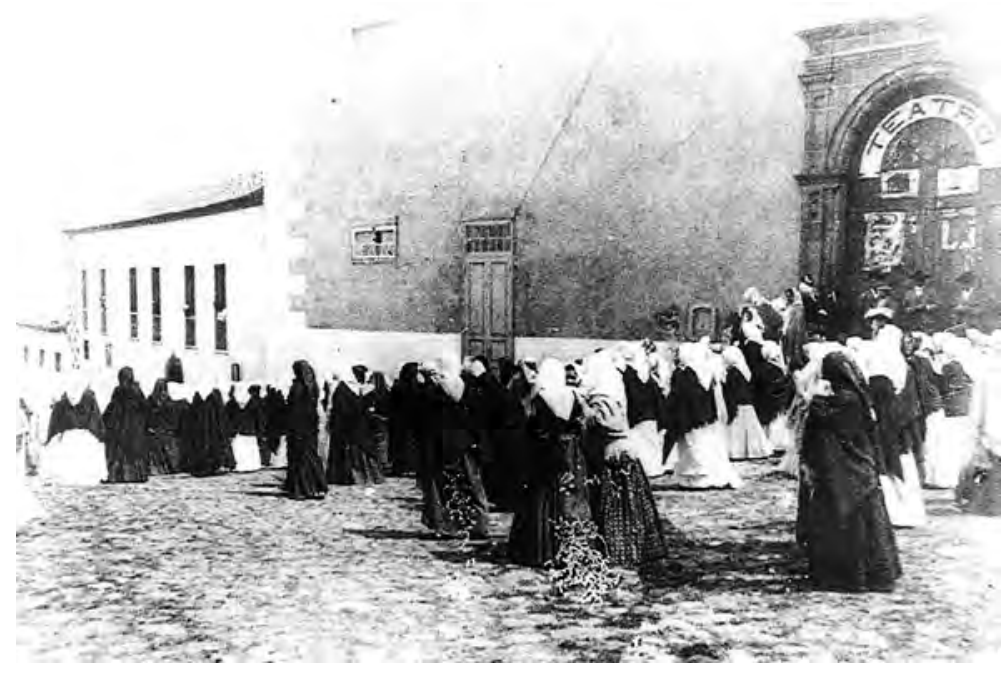

Foto 1. Procesión al paso por el Teatro Power.

del Ayuntamiento en 1842, tras el incendio del antiguo colegio jesuita ${ }^{1}$; cárcel desde 1850 , según proyecto de Manuel de Oraá que nunca se llevó a cabo realmente ${ }^{2}$; plaza de mercado desde 1874; o ciudadela hasta bien entrado el siglo xx. Incluso el beaterio pasó a uso privado, siendo la única parte que hoy en día sobrevive del edificio.

\section{EL TEATRO POWER ENTRE 1835 Y 1915}

La referencia documental más antigua que hemos encontrado sobre la existencia de un teatro en la población se refiere a «una compañía cómica que se halla en Canarias y se traslada a la villa de La Orotava", publicada a mediados de $1835^{3}$. No se especifica nada respecto al lugar de sus actuaciones pero es evidente que existía un espacio en el que poder hacer representaciones teatrales; y podemos pensar que se trataba de la compañía de cómicos peninsulares que habían llegado a la isla en $1833^{4}$.

1 Rodríguez Bravo, Jesús (2015): Los jesuitas y las artes en La Orotava, La Orotava, LeCanarien ediciones.

2 Luque Hernández, Antonio (1998): La Orotava, corazón de Tenerife, La Orotava, Ayuntamiento de La Orotava, p. 269.

3 Boletin Oficial de Canarias, 20 de junio de 1835.

${ }^{4}$ Ramos Arteaga, José Antonio (2013): Calle, plazas y salones: textos y espectáculos teatrales en el Tenerife de la primera mitad del siglo XIX, San Cristóbal de La Laguna, Servicio de Publicaciones de la Universidad de La Laguna. Soportes audiovisuales e informáticos. Serie tesis doctorales, p. 87. 
Es el semanario La Aurora el que nos ofrece alguna noticia más al respecto, en una serie de artículos sobre el teatro en Tenerife y publicados entre septiembre y octubre de 1847, en los que se dice que el teatro de la villa de La Orotava tenía en 1837 nada menos que 260 asientos 5 . La existencia de este recinto desde esas tempranas fechas queda confirmada por la petición que en 1842 hizo Nicolás Regalado para que se le cedieran el teatro y la academia de música que él mismo tenía desde hacía tiempo en el antiguo "ofertorio del convento dominico»". Parece referirse al convento de San Benito y no al de San Nicolás, pues el primero también había sido sede provisional del Ayuntamiento tras el incendio del colegio jesuita de San Luis Gonzaga en 18417. Y señala Rodríguez Mesa que al menos desde 1847 el local donde se desarrollaban esas inquietudes artísticas había pasado a depender del municipio pero no fue hasta 1855 cuando la corporación decidió formalizar la existencia de un teatro en condiciones, proponiendo para ello la vacía iglesia del convento de San Nicolás Obispo ${ }^{8}$.

Por lo tanto, existió en La Orotava un teatro con bastante capacidad, ubicado en la planta baja del convento de San Benito, al menos desde 1835, donde debieron realizarse las primeras representaciones de teatro convencional y que al menos desde 1847 pasó a denominarse Teatro Municipal; pero no fue hasta 1855 cuando se estableció en la iglesia de San Nicolás, donde permaneció hasta su desaparición a mediados del siglo $\mathrm{xx}$, como veremos.

Debemos suponer que al menos desde ese año comenzaron las actividades en aquella iglesia, que tuvo que ser transformada para acogerlas ${ }^{9}$. Sin embargo, no es hasta 1860 cuando tenemos noticia de que la sociedad La Esperanza solicitó al Ayuntamiento que el recinto que había sido ocupado por el teatro pasara a ser un teatro municipal regular, en el que hubiera de manera continua representaciones y espectáculos, que la propia sociedad fomentaba ${ }^{10}$. De hecho, llegaron a constituir una comisión que se encargase de preparar el local y el personal necesario para llevarlo a cabo y con lo recaudado en las funciones sufragar los gastos de acondicionamiento del teatro. Por lo tanto podemos afirmar que desde esa fecha y hasta finalizado el siglo XIX se sucedieron los espectáculos con bastante frecuencia, por lo que el teatro adquirió una importancia capital en la vida de La Orotava, tal y como evidencian las constantes referencias encontradas ${ }^{11}$.

5 La Aurora, 17 de octubre de 1847. Firmado por B.R.

${ }^{6}$ Dato referido por Rodríguez Mesa, Manuel (1976): 1842-1942. Un siglo de música en la villa de La Orotava, La Orotava, Agrupación musical Orotava, p. 11. Se acepta la petición, ya que el citado ha corrido con los gastos de reforma del local y no se le exige alquiler.

7 Rodríguez Mesa: op. cit., p. 11 y siguientes, y Rodríguez Bravo, op. cit.

8 Rodríguez Mesa: op. cit., p. 13.

9 Desde 1841 comenzaron a venderse los retablos. Véase Rodríguez Bravo, Jesús (2015): "Arte y perpetuidad: José de Montenegro y la capilla de ánimas del convento de San Benito de La Orotava», en Revista de Historia Canaria, San Cristóbal de La Laguna, Universidad de La Laguna, p. 202.

${ }^{10}$ Rodríguez Mesa: op. cit., p. 13 y siguientes.

11 Sirva de ejemplo que en 1863 actuó una compañía de zarzuela que se vio mermada por la fiebre amarilla (El Guanche, 22 de abril de 1863); en 1869 una compañía de declamación procedente 
El empuje dado al nuevo concepto de ocio tuvo incluso un intento de construir otro teatro, esta vez de nueva planta. Fue en 1869, cuando el arquitecto Pedro Maffiotte, a quien se debió el proyecto para el nuevo Ayuntamiento presentado ese ańo, pretendió construir un teatro y una plaza de mercado en la parte trasera del futuro consistorio, en el lugar que más tarde ocuparía la Hijuela del Jardín Botánico. Las penurias de este proyecto dieron al traste con la idea, aunque en beneficio de la sociedad se creó el citado jardín.

El paso del tiempo, el continuado uso del teatro municipal y la presencia de compañías teatrales en la isla, con las consiguientes actuaciones en la villa, obligaron a tomar medidas sobre las condiciones que reunía un local que no había sido concebido para ese uso, lo que dio pie a sucesivas reformas. Se trataba de lavados de cara de la antigua iglesia, mejoras técnicas o ligeros cambios estéticos fruto de las modas del momento. Por ejemplo, en 1869 se estaba mejorando bajo la tutela de Francisco Mela, en previsión de la actuación de una próxima compañía que solo podrá hacerlo "cuando se concluya de arreglar el teatro de La Orotava»" ${ }^{12}$. A mediados de 1871 Felipe Hernández, director de la Sociedad de Declamación «nuevamente establecida" solicitó al Ayuntamiento su cesión para el uso de la misma y que los beneficios obtenidos se destinasen a la obra de la plaza de San Sebastián. Similar petición a la hecha por un grupo de 24 individuos, esta vez para «declamación, gimnacia y música" y con el fin de comprar instrumentos ${ }^{13}$.

Las obras de mejora favorecieron que el local se convirtiese en punto ineludible de todas las compañías que recalaban en Canarias, pasando a formar parte del nutrido grupo de espacios escénicos con los que comenzaba a contar el valle ${ }^{14}$.

Intervención destacada debió tener Julio Vázquez y Díaz de Aguilar, que entre 1881 y 1887 reformó a su costa el teatro en dos ocasiones, colocando techos

de Santa Cruz (La Asociación, 1 de mayo de 1869); o la compañía del señor Mela, con el actor cómico Espinosa y la bailarina Petra Cámara (La correspondencia isleña, 26 de enero de 1869).

${ }_{12}$ Eco del Comercio, 17 de abril de 1869.

13 Archivo Municipal de La Orotava (en adelante AMLO), Libro de actas, 19 de julio de 1871, f. 63v. A comienzos de 1872 el presidente de La Fraternidad decidió contribuir con 15 pesetas por cada "función dramática, siempre que el Ayuntamiento ponga el local y los enseres». Se refería al coste de las obras realizadas a su cargo como mejora de cara a las funciones teatrales, AMLO, Libro de actas, 4 de febrero de 1872 , f. 4 . A finales de 1880 se afirmaba que se trataba «de transformar una antigua iglesia en salón de teatro, en los que los socios del casino podrán representar comedias», Revista de Canarias, 8 de noviembre de 1880; a comienzos de 1882 se comisionó a Ignacio Llarena y Monteverde y Gonzalo Cáceres para hacer un reglamento de régimen y administración del teatro, AMLO, Libro de actas, 19 de enero de 1882, f. 5v.; en junio de 1882 Francisco Benítez de Lugo y otros vecinos pidieron que se les arrendase por 200 pesetas anuales, llevando a cabo las decoraciones y reparaciones necesarias, lo que se le concede por dos años, AMLO, Libro de actas, 20 de julio de 1882, f. 28.

${ }^{14}$ Se celebraban todo tipo de actuaciones, tanto musicales como actos literarios, sesiones de magia o dramáticas. Rodríguez Mesa, op. cit., p. 87; La Orotava, 23 de junio de 1885; en 1889 actuó el prestidigitador Fournier «ante numerosa concurrencia», El Valle de Orotava, 14 de mayo de 1889; en 1896 la compañía de zarzuela de Pablo López, Diario de Tenerife, 16 de marzo de 1896 y La Opinión, 20 de marzo de 1896; en ese mismo año se reúnen varias personas en el teatro con el objeto de fundar una sociedad de avicultura, La Opinión, 20 de octubre de 1896. 


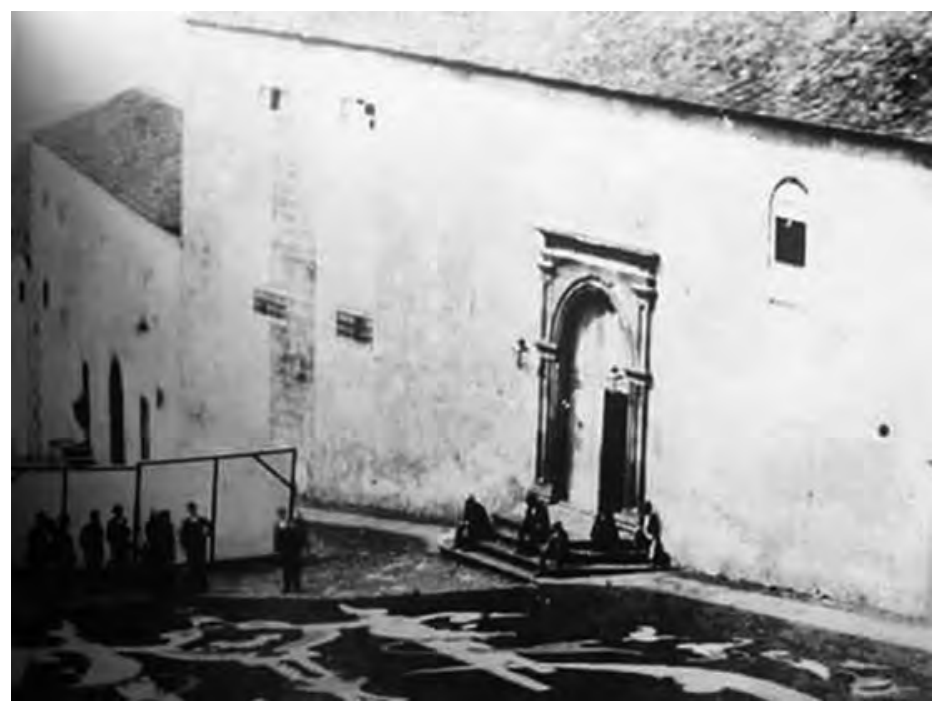

Foto 2. Fachada del teatro en la fiesta de las Alfombras.

rasos en las galerías y el atrio, o instalando el alumbrado del escenario, entre otras mejoras. Para agradecer estos servicios el consistorio le concederá varios meses después el uso vitalicio del palco bajo n. ${ }^{0} 5^{15}$.

En esos años actuó en el teatro el compositor que luego le daría nombre, el orotavense Teobaldo Power (1848-1884). El ilustre músico interpretó la obertura de su celebérrima obra Cantos canarios, junto con piezas de Suppé, Gounod, Liszt o Rossini, acompañado de otros músicos y profesores y un recital poético a cargo de Antonio Zerolo ${ }^{16}$. Con motivo de su prematura muerte, acaecida con tan solo 36 años de edad, se intentó erigir un monumento en su memoria, pero el Ayuntamiento de La Orotava se negó por carecer de fondos ${ }^{17}$.

A comienzos de 1890 se nombró una comisión llamada de teatros y espectáculos públicos para la «administración y conservación del teatro de esta Villa, así como de su mobiliario y efectos correspondientes al mismo»" ${ }^{18}$; en mayo se empapeló el

15 AMLO, Libro de actas, 5 de octubre de 1881, f. 65; 27 de octubre de 1883, f. 47v.; y 24 de agosto de 1884, f. 41v. En abril de 1889 actuó el joven intérprete Ralph Livings al piano, del conservatorio de Munich: «Además para que el triunfo obtenido por el célebre pianista fuese completo, tomaron parte en el concierto Mrs. Hamilton y la simpática joven Miss Livings, cantando ambas varias obras del mismo concertista y de los maestros Bcuderi y Henselt con suma maestría y afinación, obsequiándolas el público con preciosos ramilletes, en medio de justos y merecidos aplausos», El Valle de Orotava, 6 de noviembre de 1887 y 30 de abril de 1889.

${ }_{16}$ Revista de Canarias, 23 de diciembre de 1880.

17 Rodríguez Mesa: op. cit.

18 AMLO, Libro de actas, 12 de febrero de 1890, f. 11v. 
salón, en el marco de las reformas que seguía necesitando el edificio ${ }^{19}$. Se trataba de actuaciones englobadas en la mejora integral del antiguo convento, ya que al año siguiente se hicieron mejoras en el claustro que hacía de plaza de mercado, colocando baldosas en el suelo, mostradores con losas de mármol, surtidor para el agua de la limpieza y pintado ${ }^{20}$.

El paso del tiempo y el cambio de uso del monasterio motivaron que en 1894 Fernando Méndez y León pidiera que se cambiase el nombre a la plaza exterior al convento, hasta entonces denominada de las Monjas, por plaza del Teatro, por estar este «en su crujía principal». La moción fue aceptaba por el Ayuntamiento, ya que «no había razón para seguir llamándola así»" . Poco después se aprobó el gasto de instalación de luz eléctrica en el teatro por la Sociedad Eléctrica de La Orotava ${ }^{22}$; y dos días después se aprobó la adquisición de un solar para ensanche de las "plazas de la iglesia y teatro", incluido el derribo y la explanación del mismo ${ }^{23}$. Esta actuación se enmarcaba en la mejora del entorno de la iglesia de la Concepción, obra que incluyó el derribo del antiguo Palacio de Celada, cuyas ruinas seguían dominando el entorno.

En 1898 la revista Hespérides se hizo eco del estreno del «precioso y acabado aparato de proyecciones Cinematógafo Lumiere, que dirige nuestro estimado amigo D. Miguel Brito Rodríguez». Las exhibiciones, primeras realizadas en Canarias, se hicieron en el Círculo Mercantil con gran éxito de público y en ellas se mostraron "escenas serias, animadas y cómicas obtenidas por la luz eléctrica». La revista rogó que aquella maravilla se presentase también en La Orotava, pues la villa no podía quedarse sin «tan sorprendente espectáculo»" ${ }^{24}$. Lo cierto es que el cinematógrafo se unió desde aquel momento a la vida del Teatro Power, pero sin que otras actuaciones cedieran su lugar, algo que únicamente sucedería cuando el cine tomó cuerpo como espectáculo único ${ }^{25}$.

En junio de 1901 tuvieron lugar en el Teatro Power los famosos Juegos Florales, con poetas y escritores presididos por Benito Pérez Galdós, Ángel Guimerá y Nicolás Estévanez. Un concurso que ganó Antonio Zerolo y cuya promoción se hizo

${ }_{19}$ El Valle de Orotava, 11 de mayo de 1890. Es probable que de esa época fuese un nuevo telón, cuya decoración corrió a cargo del artista Álvarez Casanova, el mismo a quien en junio de 1899 se le encarga «la restauración del dibujo por él ejecutado gratuitamente en el telón de la boca del Teatro de esta Villa», Boletín Oficial de Canarias, 9 de octubre de 1899.

20 El Valle de Orotava, 3 de diciembre de 1891. Patricio García.

${ }^{21}$ AMLO, Libro de actas, 10 de agosto de 1894, f. 72. Actualmente lleva el nombre de

22 AMLO, Libro de actas, 15 de noviembre de 1895.

23 AMLO, Libro de actas, 17 de noviembre de 1895.

${ }_{24}$ Publicado en Hespérides, 24 de mazo de 1898.

${ }^{25}$ En 1899 se celebró un concierto de música clásica, con actuaciones del Sexteto Taoro, el Orfeón de la Villa y un grupo de zarzuela, La Región Canaria, 1899. En junio de 1900 el Liceo de Taoro organizó una velada musical con motivo de las fiestas de San Isidro, La Región Canaria, junio de 1900; también actuó ese año el ilusionista Onofroff con «experimentos de transmisión de la voluntad e hipnotismo", La Región Canaria, 1900; y se hicieron distintos actos con motivo de las fiestas locales, Unión Conservadora, junio de 1900. 
en todos los periódicos de la época ${ }^{26}$. Se calificó el acto como «lo más importante, trascendental y hermoso» que se hubiese celebrado jamás en La Orotava, afirmándose que el «lindo teatro de la Villa, reformado y completamente restaurado, presentaba un encantador golpe de vista $»^{27}$. De esa misma época parece ser una iniciativa, de la que informó a mediados de ese año el periódico El porvenir agrícola de Canarias, sobre que se pretendía construir un teatro por acciones en La Orotava ${ }^{28}$. De este tema hablaremos en el siguiente apartado, aunque la información al respecto es escasa. En cualquier caso, no tuvo efecto y nunca se pudo materializar ese deseo, vinculado posteriormente al arquitecto Mariano Estanga.

En esta primera década del siglo xx se sucedieron las actuaciones en los teatros del valle de La Orotava. Se celebraban bailes y actos benéficos, como los realizados con motivo del Carnaval en 1903 o a favor del hospital de la villa en $1905^{29}$. A comienzos de 1906 se anunciaba «un nuevo e interesante espectáculo con que deshacer nuestro constante aburrimiento: nos referimos al cinematógrafo y osquestrófono, modernos aparatos llegados últimamente a estas islas y que nos producen efectos de atracción y cautividad ${ }^{30}$. Y en mayo de 1910 se informaba que "en el patio del exconvento de monjas hizo anoche su primera exhibición el Cinema Velox» ${ }^{31}$. Este tipo de exhibiciones solían hacerse en primavera o verano si el teatro no reunía las condiciones, como en el caso del convento del Puerto de la Cruz, y en ocasiones suponían la proyección de numerosas películas de corta duración ${ }^{32}$. La mayoría de estas compañías y películas eran presentadas tanto en el Puerto de la Cruz como en La Orotava. No obstante, la ciudad turística no contaba con un teatro formal, por lo que desde 1910 la prensa se hace eco de la necesidad de construir un teatro en aquella ciudad y no será hasta que entre en escena el Thermal Palace cuando el Puerto cuente con un salón para teatro con capacidad para 400 personas $^{33}$.

26 Unión Conservadora, 7 de junio de 1901.

${ }^{27}$ Diario de Tenerife, 17 de junio de 1901.

28 El porvenir agrícola de Canarias, 29 de junio de 1901.

29 O la «Temporada teatral durante la estancia de extranjeros, 40 funciones, a 25 pesetas cada una. Bailes, cinematógrafo y otros espectáculos en el Teatro", anunciada en 1909 para la sala del Puerto de la Cruz, El Valle, 26 de febrero de 1903; El Clarin, noviembre de 1905; y El Teide, 23 de octubre de 1909.

${ }^{30}$ El Valle, 9 de marzo de 1906.

31 «Agradaron mucho las películas Caballo desbocado, Julia en el cuartel, Circo en miniatura, de magia en color y muy original y Joven virtuoso, interpretada por el célebre actor Max Lynder. También hubo buena aceptación la coupletista Clavelina que canta con mucho gusto. El programa para esta noche es de gran novedad y muy sugestivo. Se exhibirá el Cinéfono con la gran jota aragonesa cantada por el Mochuelo y la Gatita blanca, por la Soler. La concurrencia anoche fue bastante numerosa». Publicado en El Teide, 11 de mayo de 1910.

32 «Esta noche habrá función de Cinematógrafo y Cinéfono en un programa monstruo... Se presentarán 16 películas y de ellas 10 estrenos. Los precios son reducidísimos». Publicado en El Teide, 18 de mayo de 1910.

33 Este interesante edificio, terminado en 1912 y construido en la costa de Martiánez, unía el concepto de balneario con el de hotel y contaba con un salón regio, decorado por el pintor Francisco Bonnín y que también estaba acondicionado para cinematógrafo. El Teide se hace eco en 


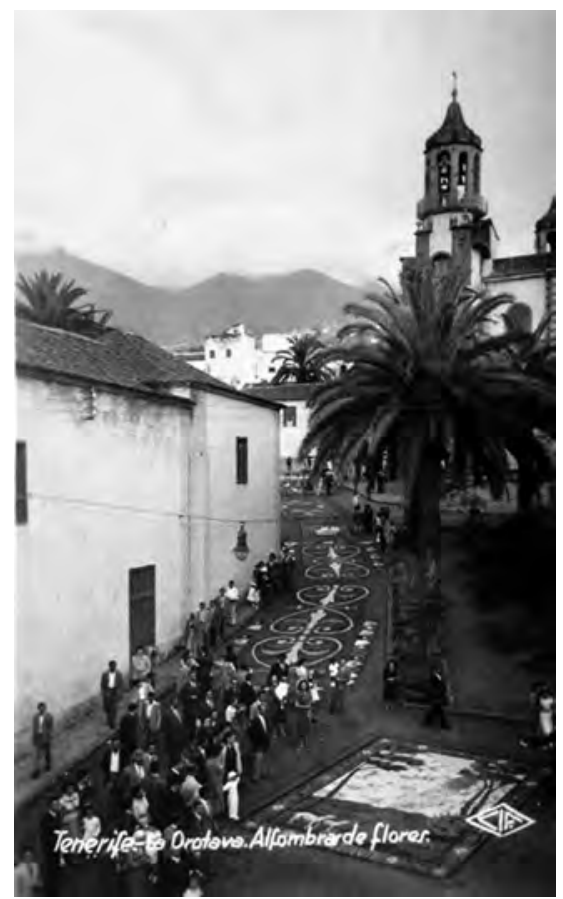

Foto 3. Postal en la que puede verse la capilla mayor de la iglesia de San Nicolás, que hacía las veces de escenario.

Es precisamente en 1912 cuando el Gobierno dicta una Real Orden sobre la moralidad de las películas exhibidas en los teatros, a raíz de las quejas de algunos diputados en el Congreso. La ley prohibía la asistencia de menores de diez años a las sesiones nocturnas, velaba por que aquellos incipientes cines no se convirtieran en foco de prostitución y suponía el inicio de cierta censura cinematográfica. En 1913 se dio un paso más, creando una comisión encargada de examinar las películas que se proyectaban. Los periódicos de la época se hicieron eco de estas circunstancias, como cuando en marzo de 1913 El Liberal, editado en el Puerto de la Cruz, publicó la clausura de los teatros en Gran Canaria pero aclarando que se había autorizado que el Teatro Power pudiese seguir abierto, al menos hasta mayo, junto con otros espacios escénicos del norte de la isla ${ }^{34}$.

numerosas ocasiones de este asunto. Incluso llega a decir que el proyector del Thermal Palace era el mejor que existía en Canarias.

${ }_{34}$ El Liberal, 8 de marzo de 1913. De hecho, este mismo periódico anunciaba a mediados de abril la celebración «de dos funciones cinematográficas con películas atrayentes de la casa alicantina perteneciente a D. José María Marín, siendo empresario el Sr. Bellidos, que hace dos semanas viene 
A mediados de 1908 se pidió la cesión total del convento de San Nicolás al Ayuntamiento de La Orotava, que desde el 13 de octubre de 1843 tenía en uso para mercado, escuela y cárceles ${ }^{35}$.

\section{LA REFORMA DE ANTONIO PINTOR Y EL PROYECTO DE MARIANO ESTANGA}

Aunque el Teatro Power llevaba cumpliendo sus funciones como sala de espectáculos más de cincuenta años, la realidad era que el acondicionamiento que se había hecho de la iglesia no reunía las condiciones necesarias ni cumplía la normativa. La primera gran reforma del recinto tuvo lugar al finalizar el siglo XIX y consistió en la creación de una línea de sencillos palcos a ambos lados de la nave, una zona de gradas en el antiguo coro conventual y la reforma del escenario. A este proyecto se le añadió la mejora de la sacristía como lugar para los camerinos. La obra se le encargó a Antonio Pintor, arquitecto que en ese momento se encontraba trabajando en el nuevo Ayuntamiento y que había obtenido la plaza de arquitecto municipal de Santa Cruz de Tenerife en 1889. El diseño era muy sencillo pero también el más profundo que había tenido la antigua iglesia de San Nicolás. Testimonios orales que hemos recogido recuerdan cómo esa era la distribución que tenía aún en los años 40 del siglo xx, por lo que se trató de la mayor y más duradera reforma que sufrió el Teatro Power ${ }^{36}$.

No obstante, las pretensiones eran otras y por esa razón en 1915 se encargó al arquitecto Mariano Estanga una reforma del recinto destinada a lograr tener un teatro "de mayor capacidad y belleza» ${ }^{37}$. Para ello se formó una comisión gestora que a través de la venta de acciones pretendía financiar el proyecto. En el primer trimestre de ese año consiguió colocar acciones por valor de 50000 pesetas, pero no fueron suficientes. La obra se entendía en el marco de la reforma de la plaza de Casañas, «en un sitio que ocupaban las ruinas de un antiguo palacio incendiado, frente a la parroquia matriz ${ }^{38}$. Es probable que Estanga entendiera, como hará posteriormente Marrero Regalado, que cualquier proyecto de nueva planta debía incluir el espacio ubicado hacia el sur, justo donde se había colocado la plaza y sobre los cimientos del Palacio de Celada. De esta manera, aquella haría de pórtico de entrada al teatro, como una antesala ajardinada. Sin embargo, la iniciativa no tuvo mayor recorrido,

ofreciendo al público orotavense escogidos asuntos y una magnífica proyección de admirable fijeza por medio de su cine Gaumont. Todo será de absoluta novedad». Publicado el 14 de abril de 1913.

35 AMLO, Libro de actas, 13 de agosto de 1908, f. 8v.

36 Testimonios orales de Carmen Bravo González, María Luisa González Abreu y Secundino Domínguez González, recogidos en 1995.

37 La Prensa, 11 de marzo de 1915.

38 «El teatro, situado en la plaza de las Monjas, y en cuyo punto se trata de construir otro de mayor capacidad y belleza, habiéndose nombrado al efecto una Comisión gestora que hasta ahora ha logrado colocar acciones por valor de 50.000 pesetas, y ha encargado el plano correspondiente al arquitecto Sr. Estanga», La Prensa, 11 de marzo de 1915. 


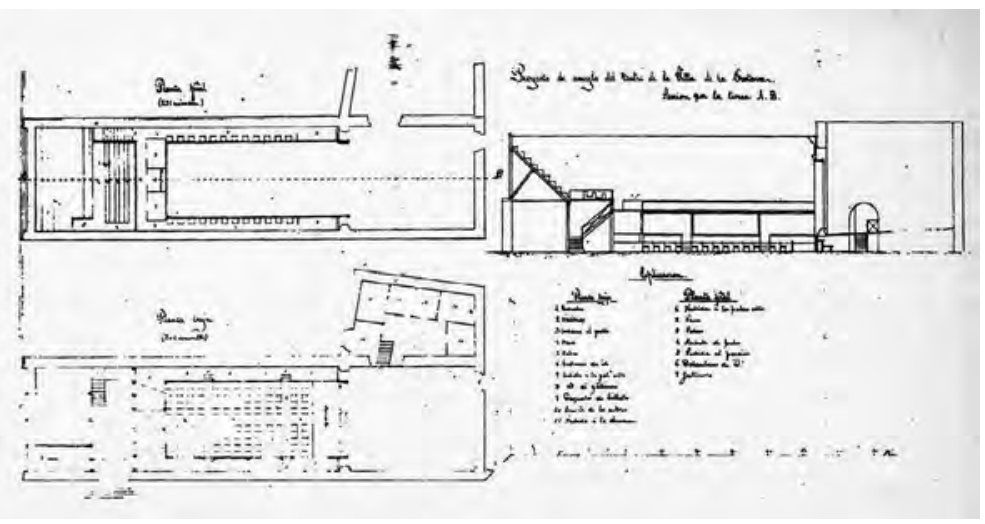

Foto 4. Plano y alzados de la reforma de Antonio Pintor.

tal vez porque lo recaudado no fuese suficiente o porque el momento no era el más adecuado; hacía poco que había comenzado la Primera Guerra Mundial. Y aunque Mariano Estanga realizará otras intervenciones en La Orotava en ese momento, como la proyectada en la plaza de la Paz, lo cierto es que todas se vieron influidas por los problemas derivados de la contienda. Precisamente a finales de ese mismo año el Ayuntamiento concedió una prórroga para la explotación del «Coliseo del Municipio» hasta el fin de 1916 a la Gestora del Nuevo Teatro, permitiéndole ejecutar reformas. Tal vez se tratase de los mismos promotores que habían encargado el proyecto a Estanga, ante la imposibilidad de realizarlo ${ }^{39}$.

En cualquier caso, la actividad no se vio afectada y continuaron las exhibiciones cinematográficas y las actuaciones teatrales. Una de las que más repercusión tuvieron fue la de Lola Montes en 1922, de la que dio cumplida cuenta la prensa de la época. La famosa cantante había iniciado una gira que la llevaría a América, tras su éxito en los teatros de $\mathrm{Madrid}^{40}$.

\section{EL PROYECTO DE JOSÉ ENRIQUE MARRERO REGALADO}

En junio de 1926 el Ayuntamiento, bajo la presidencia de Cándido Pérez Estrada, aprobó por unanimidad el proyecto de un nuevo teatro municipal redactado por el arquitecto José Enrique Marrero Regalado (1897-1956) ${ }^{41}$. El nuevo edificio era el primer encargo de este artista en el archipiélago y debía ocupar el solar del

\footnotetext{
39 AMLO, Libro de actas, 2 de diciembre de 1915, f. 99v.

40 El norte de Tenerife, 4 de mayo de 1919; Heraldo de Orotava, 31 de diciembre de 1922.

41 Se le había encargado en mayo de ese año. AMLO, Libro de actas, 19 de junio de 1926.
} 
antiguo Teatro Power y la plaza del mercado. En la memoria presentada a la corporación Marrero Regalado decía que «el salón, antiguo convento acondicionado para teatro, ha venido cumpliendo deficientemente tal cometido. Este, en general y, sobre todo, el patio de butacas reúne pésimas condiciones sanitarias, aparte de encontrarse totalmente al margen de cuanto previene el Reglamento de espectáculos acerca de esta clase de edificios» ${ }^{42}$. El proyecto culminaba las aspiraciones de La Orotava de tener un coliseo digno y estaba llamado a convertirse no solo en el teatro de la villa, sino también en el teatro del valle. Sin embargo, las dificultades económicas por las que atravesaba el Ayuntamiento demoraron indefinidamente su construcción y ya en 1928 el concejal Félix Rodríguez Martín admitía que la obra no podía llevarse a cabo hasta que «las condiciones económicas de su hacienda se lo permitan». El mismo consistorio parecía confirmar tal circunstancia cuando en la sesión de enero de ese año acordaba también por unanimidad arrendar el teatro del municipio a Antonio García y García «para la celebración de espectáculos, con las condiciones de tiempo de duración del arriendo, precio y otros que propone, incluyéndose entre ellas la de que se autorice, como en años anteriores, para celebrar en la plaza de Alfonso XIII espectáculos de cinematógrafo en el lapso de tiempo comprendido desde la terminación de las fiestas hasta la primera quincena de octubre» ${ }^{43}$. Esta decisión se reforzó aún más en el mes de diciembre cuando se concedió a Manuel González González el patio que existía entre el teatro y la plaza de mercado durante diez ańos, para la "celebración de algunos espectáculos, como riñas de gallos, luchas y otros análogos» ${ }^{44}$. De esta manera, dos años después de haberse aprobado el proyecto, este parecía abandonarse definitivamente.

Marrero Regalado había acabado su carrera en la Escuela de Arquitectura de Madrid en 1925 y entre ese año y 1933 desarrolló su labor como arquitecto en la Península, vinculado a artistas como Pascual Bravo Sanfeliú, Luis Gutiérrez Soto o los hermanos Julián y Joaquín Otamendi ${ }^{45}$. Sus proyectos se extenderán a varias ciudades, entre ellas Madrid, Sevilla y Bilbao, viéndose notablemente influidos por las últimas manifestaciones de un eclecticismo con marcado carácter regional y los inicios del movimiento moderno. Con Gutiérrez Soto realizará el Cine Callao de Madrid en el mismo año que el proyecto del nuevo Teatro Power, pero nada tienen que ver uno con otro en su planteamiento exterior. El primero se deja influir por las líneas art déco mientras el segundo estaba inspirado en el estilo neorrenacentista, muy en la línea de la estética de los hermanos Otamendi en el País Vasco, por otra parte, de un profundo regionalismo. El proyecto de Marrero Regalado para La Orotava

${ }^{42}$ El proyecto se sometió a exposición pública durante quince días en los que no recibió alegaciones. Marrero Regalado cobró 10000 pesetas por su redacción. AMLO, Libro de actas, 19 de junio de 1926. Fue publicado en el Boletín Oficial de Canarias, 22 de octubre de 1926.

43 AMLO, Libro de actas, 20 de enero de 1928.

${ }_{44}$ AMLO, Libro de actas, 14 de diciembre de 1928.

45 Véase Ruiz Rodríguez, Álvaro (1992): «El arquitecto Marrero Regalado: formación y primeros proyectos. Madrid (1925-1933)», en Homenaje al profesor Hernández Perera, Madrid, Universidad Complutense, p. 151. 
tenía más de palacete que de sala de espectáculos. Y aunque las líneas generales del edificio recuperaban elementos renacentistas, no dejaba de tener un aire regional, aún poco definido y que tanto destacará en sus obras posteriores. Incluso vemos influencia de los diseños de Aníbal González para algunos de los pabellones de la Exposición Iberoamericana de Sevilla de 1929, como el llamado pabellón mudéjar o algunos detalles del pabellón del Renacimiento, sobre todo en los remates y los vanos. Decían los regidores municipales que el diseño del arquitecto debía tener en cuenta el emplazamiento, la capacidad, la comodidad y la sencillez y que su estilo arquitectónico era el «predominante en nuestros edificios públicos y particulares» ${ }^{46}$. Se referían, evidentemente, a los ejemplos salidos de la mano de Mariano Estanga, Antonio Pintor o Nicolás Álvarez Casanova en esos años, dentro de la estética ecléctica historicista y que habían revolucionado el panorama edificatorio de la población entre los últimos años del siglo xix y las primeras décadas del Xx.

El edificio debía ocupar un solar de aproximadamente 900 metros cuadrados, perimetrados por dos fachadas monumentales, la principal de 26 metros y la lateral de 34, con una capacidad de unos 3000 metros cúbicos, lo que permitía acoger a un número significativo de espectadores y una amplia caja escénica. La fachada principal daba a la plaza de Casañas, que haría las veces de pórtico vegetal y estaba enmarcada por dos torreones laterales y un espacio central con tres vanos acristalados y balcón corrido. Todo rematado por un frontón que recuerda mucho al utilizado por Estanga en el colegio San Isidro unos ańos antes y a su frustrado proyecto de 1915. La fachada lateral repetía un esquema similar, aunque llegaba a tener cinco vanos en la parte inferior y se le anexaba un bloque lateral independiente de clara influencia italiana. Interiormente se proyectaba un amplio vestíbulo que hacía las veces de distribuidor de los espacios, del que salía una galería que rodeaba al patio de butacas y en la que se incluían diez palcos y antepalcos. Lo mismo sucedía en el entresuelo, donde se ubicaban diecisiete palcos, incluido el destinado al Ayuntamiento. Tenía además una planta principal y otra planta superior con cinco palcos laterales en cada una, antepalcos y galerías. En total presentaba un aforo para 886 localidades y un presupuesto de 474881,50 pesetas $^{47}$.

De las dificultades económicas para llevarlo a cabo da cuenta el hecho de que en ese mismo año no se pudieran satisfacer a Ananías Hernández Delgado las 262,50 pesetas por las reformas hechas en la plaza del mercado, aunque se destinó casi el doble a "gastos de conservación, reparación y reformas del edificio Teatro»" ${ }^{48}$. Sin embargo, en febrero de 1927 se inauguró el Teatro Topham del Puerto de la Cruz, obra de Antonio Pintor, que culminaba un anhelo de la ciudad desde hacía muchos años; y en 1932 se presentó el diseño de José Blasco para el malogrado Teatro Atlante, promovido por Antonio García García. Este había presentado un proyecto anterior de otro arquitecto con una parte cubierta y otra al aire libre, pero finalmente fue el

\footnotetext{
${ }^{46}$ Palabras del concejal Féliz Reyes Martín en La Voz del Valle, número extraordinario, 1928.

${ }^{47}$ Los datos se incluyen en el citado artículo de La Voz del Valle.

48 AMLO, Libro de actas, 26 de marzo y 22 de mayo de 1926.
} 


\section{Proyecto del nuevo Teatro de la Orotava}

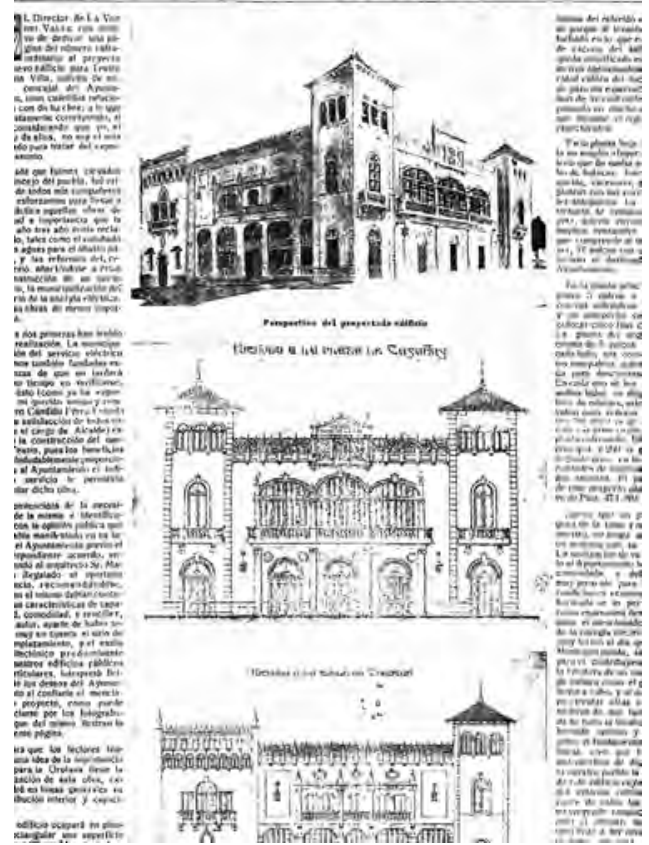

Foto 5. Artículo publicado en La Voz del Valle en 1928 sobre el proyecto de Marrero Regalado.

edificio de Blasco el que se ejecutó; un proyecto de líneas más limpias y modernas con capacidad para 850 personas ${ }^{49}$, incomprensiblemente derribado.

\section{LOS ÚLTIMOS AÑOS, EL DERRIBO Y LA URBANIZACIÓN DE LA MANZANA}

A mediados de 1926 actuó la compañía del dramaturgo Felipe Sassone, con la primera actriz María Palou, que había trabajado también en obras de Carlos Arniches, Benito Pérez Galdós, Pedro Muñoz Seca, Jacinto Benavente o los hermanos Álvarez Quintero. Era costumbre entonces que hubiese teatro siempre que llegasen compañías de la Península y dos funciones de cine, una por la tarde destinada a películas cómicas y otra por la noche, en la que solían exhibirse cintas calificadas

49 Zalba González, Eduardo (2016): «La luz de la oscuridad. Proyectos inéditos de cinematógrafos de José Blasco Robles», en XXI Coloquio de historia canario-americana, Las Palmas de Gran Canaria, Casa de Colón, Cabildo Insular, pp. 1-9. 
como cincodramas, ya que estaban divididas en cinco partes, como La cruz del Sur o El hábito, de la actriz Mildred Harris ${ }^{50}$.

Las fiestas locales también seguían siendo motivo para celebraciones en el Teatro, como las veladas literario musicales organizadas por el periódico La Voz del Valle; o conciertos de cámara, una costumbre que llegó hasta los años 50. Sin embargo, ya en esas fechas el Teatro Power no tenía la actividad que en décadas pasadas y las ideas municipales proyectadas sobre el enorme solar del convento comenzaron a abrir la posibilidad de su derribo. La primera de ellas fue la construcción de un ambulatorio justo por debajo del teatro, para cuya construcción se confeccionó un plano en mayo de $1950^{51}$; y la segunda el proyecto para un edificio de correos en el mismo lugar que la sala ${ }^{52}$.

A finales de ese año la alcaldía retiró una proposición que había hecho sobre alquilar «el Teatro Power de este Municipio, para almacenamiento de patatas» por considerar que no convenía cederlo en arrendamiento ${ }^{53}$; y pocos días después se redujo a 2000 pesetas la partida que se destinaba a la «conservación, reparación y reforma del exconvento de Monjas Catalinas ${ }^{54}$. Ya parecían estar claras cuáles eran las intenciones de la municipalidad respecto a la manzana urbana ${ }^{55}$.

Desde ese momento las actuaciones sobre lo que quedaba del convento se suceden muy rápidamente. A finales de 1951 se le comunicó a la Dirección General de Correos y Telecomunicaciones que el Ayuntamiento optaba por construir por su cuenta el edificio destinado a ese fin, a pesar de que se le había hecho cesión gratuita del solar ${ }^{56}$. También se habla de la conveniencia de construir un grupo escolar con ocho aulas y ocho viviendas para maestros en la parte situada en la confluencia de las calles Paloma y Cólogan ${ }^{57}$. A finales de julio de 1953 se propuso finalmente el derribo del convento por la necesidad de construir un ambulatorio ${ }^{58}$ y la Dirección General de Correos y Telecomunicaciones comunicó que la obra había sido adjudicada "por el Exmo. Sr. Ministro de la Gobernación a Construcciones Zuri...» y se había nombrado «ayudante técnico del Arquitecto Director al Aparejador Don Federico Miret Sánchez...», comprometiéndose el Ayuntamiento a que el solar se entregase "completamente explanado y con sus calles de acceso ensanchadas y urbanizadas, conforme al respectivo plano autorizado por el Arquitecto Don Tomás Machado. Y que, en consecuencia, urge llevar a cabo la demolición de la parte del exconvento de monjas

50 La Prensa, junio de 1926.

51 AMLO, Libro de actas, 17 de mayo de 1950.

52 En agosto de 1950 se pide a la Dirección General de Correos que concrete el tiempo de construcción del edificio de correos. AMLO, Libro de actas, 30 de agosto de 1950.

${ }_{53}$ AMLO, Libro de actas, 6 de diciembre de 1950.

54 AMLO, Libro de actas, 29 de diciembre de 1950.

55 AMLO, Libro de actas, 5 de abril de 1951. A pesar de ello se aprobaron por unanimidad las «indispensables reformas en el vestíbulo del Teatro Power, a fin de habilitar un local para oficina del Servicio Eléctrico».

56 AMLO, Libro de actas, 23 de noviembre de 1951.

${ }^{57}$ Según proyecto de Tomás Machado y Méndez-Fernández de Lugo. AMLO, Libro de actas, 8 de octubre de 1952 y 2 de octubre de 1953.

58 AMLO, Libro de actas, 31 de julio de 1953. 


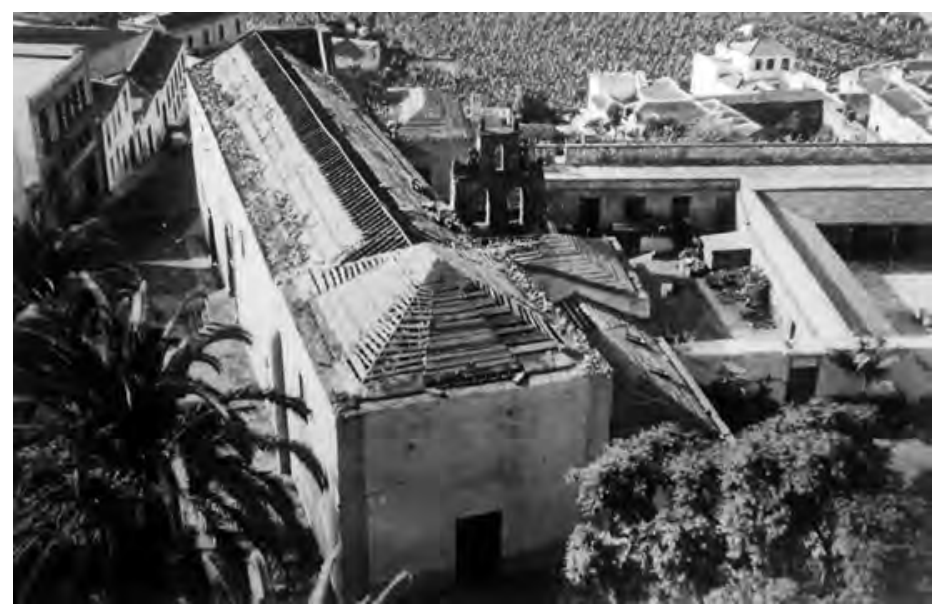

Foto 6. Derribo del Teatro Power en 1953.

Catalinas y Dominicas donde ha de construirse el referido edificio...». El Ayuntamiento reconoció la urgencia de proceder al derribo y la necesidad de aprovechar la gran cantidad de madera de tea y tejas para poder subastarlas ${ }^{59}$.

Curiosamente, en agosto de 1955 el alcalde propuso poner una calle a Teobaldo Power porque «hace ya muchos ańos que este municipio tuvo el acierto de denominar Teatro Power al antiguo Teatro Municipal de esta Villa -hoy demolido para la construcción del edificio de Correos y Telecomunicaciones-, cuyo Teatro se enclavaba donde existió el convento de Monjas Catalinas y Dominicas, de grata recordación...» y se aconsejaba colocar una placa de mármol ${ }^{60}$. Dos años después se inauguró el Cine Orotava, según proyecto arquitectónico de Enrique Marrero Regalado y cinematográfico de Manuel Fernández Padrón, bajo el encargo de José Bartlet y César Hernández ${ }^{61}$. Era el acto final de un largo proceso en el que la devoción había dado paso al espectáculo y este a nuevos usos sociales, aunque a costa de la destrucción patrimonial.

ReCibido: 21-03-2018, ACEPTADO: 10-04-2018

59 AMLO, Libro de actas, 31 de julio de 1953. En septiembre hacen cesión de las sillas del teatro a José Ponte y Méndez, AMLO, Libro de actas, 18 de septiembre de 1953. Las maderas y tejas salieron a subasta en dos ocasiones por 72990,75 pesetas. Libro de actas, 29 de marzo de 1954 y 2 de diciembre de 1954. Boletín Oficial de la Provincia, 7 de enero de 1955. Entre el 13 de septiembre y el 31 de diciembre de 1954 se derribó y desescombró parte del convento, donde en mayo de 1955 se estaba construyendo ya el centro sanitario, costando 27 476,99 pesetas a cargo de Manuel Martín Méndez, Libro de actas, 6 de mayo de 1955. En marzo de 1955 se aprobó adjudicar a Urbano Sosa Hernández el remate de palos y tablas de tea por 59225 pesetas, Libro de actas, 18 de marzo de 1955.

${ }^{60}$ AMLO, Libro de actas, 20 de agosto de 1955.

${ }^{61}$ La manzana que ocupó el convento se completó en 1963 con la construcción de los juzgados, de la mano del arquitecto Francisco Roda Calamita; y el edificio de Telefónica en 1971. 